\title{
COMMENTARY: MONETARY AND FISCAL POLICY NORMALISATION AS BREXIT IS NEGOTIATED Garry Young*
}

The global economy now appears to be enjoying a broad, synchronised and seemingly sustainable expansion. In the advanced economies, economic growth is proceeding at a moderate pace, inflation remains low and slack is being gradually used up. In the United States and Canada, where there is little slack remaining, the first tentative steps towards monetary policy normalisation are being taken.

Having been one of the fastest growing advanced economies ahead of the EU referendum in June 2016, the UK economy is now beginning to slow as others pick up the pace (figure 1). The UK economy is estimated to have grown by 1.5 per cent in the year to the third quarter of 2017. This growth rate represents a material loss of momentum from annual rates of GDP growth of around 2 to 3 per cent achieved in the years leading up to the referendum. Productivity growth has also slackened off and output per hour appears to have been flat or falling. Moreover, largely because of the significant depreciation of sterling that accompanied the decision to leave the EU, household real incomes have fallen over the same period. According to the ONS, real household disposable income per head fell by 1.1 per cent in the year to the second quarter of 2017; this was the fourth consecutive quarterly fall in this measure of real income and the longest period of consistent negative growth since the end of 2011.

It is almost certain that the relative deterioration in the UK economy and the accompanying fall in living standards over the past year are a consequence of the vote by the British people to leave the European Union. Had sterling not depreciated and the economy continued to grow at its previous rate, as would have been likely with an improving global backdrop, real household disposable income per head might have been more than 2 per cent higher than now, worth over $£ 600$ per annum to the average household. And, as pointed out by Stephen Clarke, Ilona Serwicka and L. Alan Winters in this Review, the effects of a higher cost of living caused by Brexit might weigh more heavily on unemployed, single parent and pensioner households.

It is possible to identify two key channels by which UK households on average have been made worse off by the country's decision to leave the EU.

The first has been through the depreciation of the sterling exchange rate and the effect of this on the prices of imported goods and services. The sterling depreciation can be seen as the effect of a forward-looking assessment

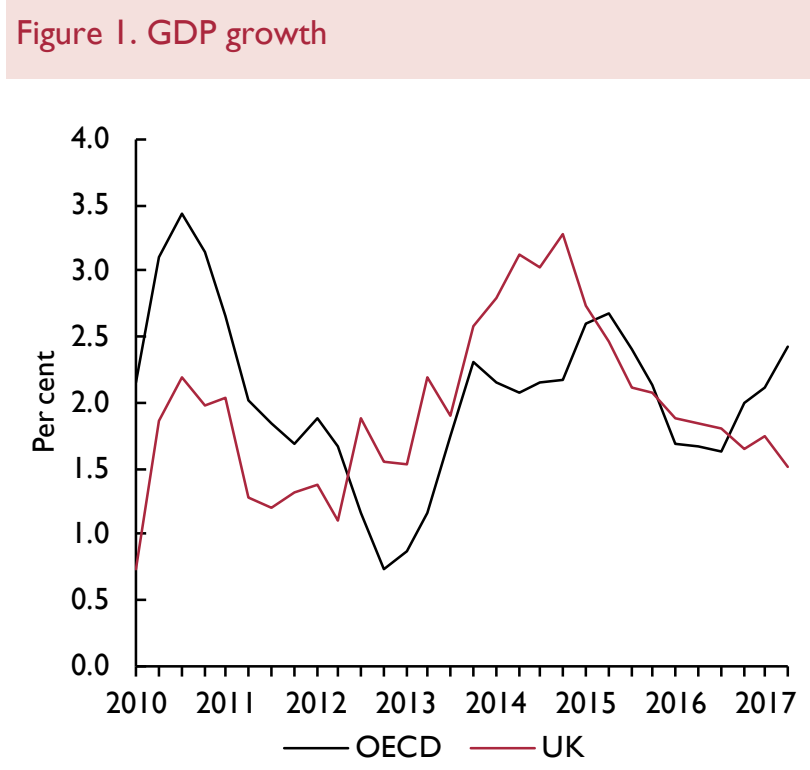

Source: ONS, NIESR and NIESR calculations; author's calculations. 
by the financial markets of how much producers of UK goods and services will be handicapped by Brexit and their need for a lower exchange rate if they are to compete. In line with this assessment, the value of sterling has tended to move in a consistent manner on news about the progress of Brexit negotiations and related policy announcements and speeches.

The second channel has been through weaker investment by UK businesses in productive capacity than might otherwise have been the case and the associated slowdown in productivity growth. On the latest figures, business investment grew by 2.5 per cent in the year to the second quarter of 2017. While this is stronger than some commentators had expected in the wake of the referendum, it represents a slowdown from faster growth rates of around 5 per cent observed over 2010 to 2015 .

A reason for businesses not investing as much as they would otherwise have done is that they have been, and remain, unsure about the terms on which they will be able to access overseas markets when the UK leaves the EU. For businesses that export a significant proportion of their output to the European Union the rate of return on investment is likely to hinge on what type of access will be available beyond 29 March 2019. Delaying investment decisions until more is known about the UK's future relationship with the EU is likely to be the appropriate response for many businesses. There is an important literature in economics explaining why it makes sense to defer irreversible investment decisions in the presence of heightened uncertainty (Dixit and Pindyck, 1994).

Some evidence on the extent to which Brexit is an important source of uncertainty for British businesses is available from the Bank of England-NottinghamStanford Decision Maker Panel (DMP) of senior executives from UK businesses (Bloom et al., 2017). Panel members from a diverse range of non-financial businesses have been surveyed on a monthly basis since the referendum and provided their assessment of current business conditions. In August 2017, 39 per cent of respondents reported that Brexit was one of the top sources of uncertainty facing their businesses. Only 13 per cent of respondents said that Brexit was not an important source of uncertainty to their business, down from 23 per cent in August 2016.

Evidence from the DMP also suggests that senior executives from British businesses see the risks to their sales from Brexit as being mainly to the downside. Asked in May-July 2017 to assess how the eventual Brexit deal would affect their sales compared to what would have happened if the UK had remained in the EU, DMP members thought there was a 45 per cent chance that sales would be lower, a 36 per cent chance that sales would be little different and a 19 per cent chance that sales would be higher. This assessment was slightly more to the downside than when the question had been asked earlier in the year.

As an important source of uncertainty with significant downside risks, Brexit is likely to be weighing on investment plans. Within business, boards are likely to be pressing executives to explain the risks, their contingency plans and thereby increasing the hurdle that investment projects need to get over if they are to be undertaken. Consistent with this possibility, DMP evidence suggests that businesses have become less positive about expected investment over the course of the year: while DMP members are expecting to increase investment over the next year, the average probability attached to it falling has risen from 28 per cent in November 2016-January 2017 to 43 per cent in August 2017. The recently published EEF/Santander Annual Investment Monitor covering the manufacturing sector also found evidence of Brexit-related uncertainty affecting investment intentions: a third of respondents said that Brexit had no impact on their investment plans, a similar proportion were only investing to satisfy current plans and waiting for clarity on any deal before investing further, while 13 per cent were holding off investment altogether until there was further clarity on a Brexit deal. David Bailey and Lisa de Propris examine the impact of Brexit on the UK automotive industry in detail later in this Review.

In addition to weakening investment intentions, Brexitrelated uncertainty has caused businesses to consider moving some of their operations abroad. This is most obviously affecting the financial sector, where UK-based institutions are currently able to use EU passporting rules to trade with EU counterparties. The possibility of losing passporting from 29 March 2019 has resulted in institutions exploring other options and considering shifting some of their operations to the EU or elsewhere. Monique Ebell, Jack Pilkington, Jeremy Rowe and Sylaja Srinivasan provide new estimates of domestic value added from financial services trade with the EU and other parts of the world, under current trading arrangements in this Review. But there is also DMP evidence that a significant minority of non-financial businesses are considering moving their operations abroad too. In May-July 2017, 21 per cent of businesses said there was a positive probability of moving some 
of their operations abroad as a consequence of Brexit. For 7 per cent of businesses the probability was more than 50 per cent, suggesting that they were more than likely to move some of their operations away from the UK. Bloom and Mizen (2017) report that many of those businesses were expecting to move within two years, before the UK has actually left the EU.

This evidence suggests that continuing uncertainty about Brexit and the possibility of an adverse change in trading arrangements in the future is affecting investment and productivity now. More information on the extent to which uncertainty is bearing down on investment and productivity is likely to be elucidated by a new and comprehensive survey of firms' expectations, carried out by ONS in collaboration with the Economic Statistics Centre of Excellence, the results of which will be available next Spring. ${ }^{1}$ Leading UK business organisations are reported to have written to David Davis, Secretary of State for Exiting the European Union, saying that "we need agreement of transitional arrangements as soon as possible, as without urgent agreement many companies have serious decisions about investment and contingency plans to take at the start of $2018 \% .2$

On page F21 we set out what assumptions we have made about Brexit in preparing our central forecast. In line with the Prime Minister's Florence speech, we have assumed that there will be an 'implementation period' of around two years after March 2019 where the UK remains a member of the EU single market. We have assumed that beyond 2021 the UK will trade with the EU on a tariff-free basis by way of a negotiated free trade agreement. Initially this would allow free trade in goods and services because UK and EU regulations would be aligned as they are now, but over time non-tariff barriers to trade would increase as regulations diverge.

Our central case therefore is a relatively 'soft' version of Brexit. We have chosen it because it seems closest to meeting the objectives of both sides in the negotiations and most likely to be acceptable to the EU and UK parliaments. With continuing free trade in goods between the EU and the UK it would also mean that there would be no need to change current border arrangements. Such a settlement would be particularly important in the case of the Northern Ireland border.

But we do not have any great confidence that this will be the path to Brexit that will be followed. There are many possible alternatives, including the extreme possibility of a disorderly cliff-edge Brexit where the UK leaves the EU with no deal in place and no legal basis for many current activities to continue.

Swati Dhingra, Stephen Machin and Henry Overman in this Review report estimates at both the aggregate and local level of the effects of two different orderly forms of Brexit. The estimated costs of Brexit are material, but not catastrophic. For example, in the long run, gross value added in the City of London, the worst affected local authority, is estimated to be reduced by 1.9 per cent by a soft Brexit, and by 4.3 per cent by a hard Brexit. In this Review Rebecca Riley and Francesca Foliano discuss the implications for the UK's industrial structure of previous changes to trading arrangements in the early 2000s. They find that the increasing openness to international trade with lower wage economies such as China and some Eastern European countries was associated with an acceleration of the secular decline in UK manufacturing.

In normal circumstances the costs associated with changing trade agreements might be disguised by underlying productivity growth in the region of 2 per cent per annum. But productivity has been flat since the financial crisis and is now around 20 per cent below its pre-crisis trend, dwarfing most estimates of the effects of Brexit. Brexit is likely only to prolong the period of productivity weakness and delay the resolution of the productivity puzzle.

\section{Fiscal policy}

The future path of productivity, and how it is affected by Brexit, remains one of the key uncertainties facing policymakers at the moment. It is particularly relevant to the setting of fiscal policy and is likely to be a key factor in framing decisions in the Autumn Budget on 22 November.

In March, the Office for Budget Responsibility (OBR) had assumed that potential growth in output per hour would pick up slowly from 1.4 per cent in 2017 to 1.8 per cent in 2021. But, in its Forecast Evaluation Report the OBR stated that it intended to revise down potential productivity growth in its November forecast, weakening the outlook for the public finances. This reflects continued disappointing outturns for productivity relative to forecast assumptions.

For similar reasons, we have also revised down the path of future productivity growth assumed in the forecast. Our central forecast is now based on the assumption that output per hour grows over the next five years at an average rate of about 1 per cent per annum, about $1 / 4$ per 
Figure 2. UK Productivity

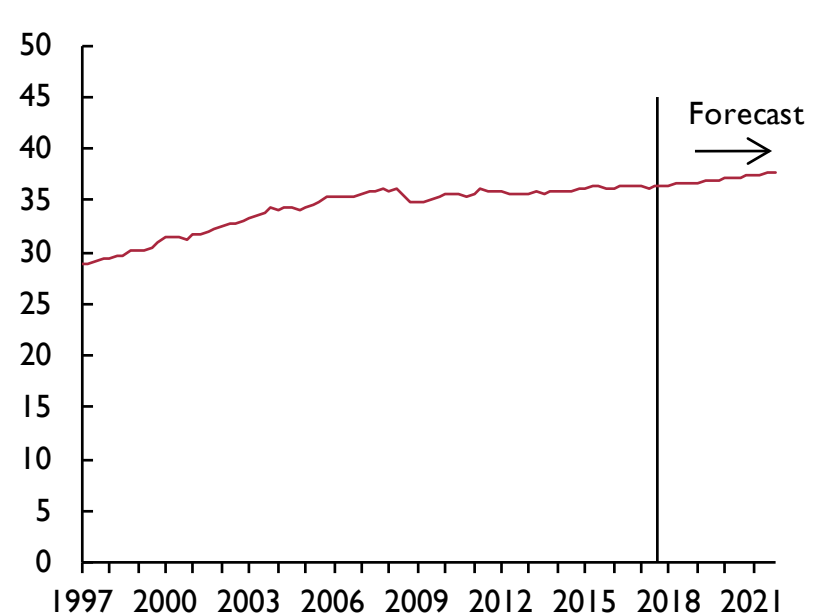

GDP per hour worked

Source: ONS and NIESR calculations.

cent per annum lower than in the August forecast. This is in line with new estimates of total factor productivity growth reported in Box D of the UK section of this Review. Even this lower rate could be seen as optimistic as it is higher than achieved in most years since the financial crisis and reflects an assumption that productivity growth will pick up once slack has been eliminated from the economy (figure 2).

On this basis and on the assumption of no change from announced government spending plans, our central forecast is that public sector net borrowing will decline from 2.9 per cent of GDP in the current financial year to around balance by 2021/2. While productivity growth is weaker than we previously assumed, nominal GDP and the tax base are not much different. As such, the government's fiscal objective, re-iterated by the Chancellor in his Mansion House speech, of achieving a balanced budget by the middle of the next decade is broadly met with time to spare. This central outlook may thereby provide some scope, as outlined on page F30 of this Review, for the Chancellor to consider measures that would normalise public spending over the forecast period, such as lifting the cap on public sector pay.

But there are clearly substantial risks around the assumption concerning future productivity growth. To the upside there is the possibility that some of the factors that caused productivity to fall 20 per cent below its pre-crisis trend reverse themselves: it could be seen as very pessimistic to assume that none of the accumulated productivity weakness is recovered over the next five years. But that possibility seems fairly remote given the earlier discussion about the uncertainty surrounding Brexit negotiations. It would seem more prudent for policymakers to consider an even weaker outlook for productivity growth.

To assess the effect of a weaker profile for productivity growth on the public finances we have constructed a variant forecast where UK productivity growth is set at zero for the two years, and recovers only weakly thereafter. The effect of the lower productivity assumption on the outlook for public sector net borrowing is illustrated in figure 3, which also contains a fan chart showing an estimate of the risks around our central forecast. The effect is that public sector net borrowing, rather than moving back to around balance, falls only to around 1 per cent of GDP. And if this scenario were combined with the additional spending measures considered on page F30, it would not fall much below current levels. In neither case would the government's medium-term fiscal objective of a balanced budget be met within the forecast period.

What should the Chancellor do if presented with such a challengingly pessimistic, but not unrealistic, fiscal outlook?

Figure 3. Probability distribution of public sector net borrowing

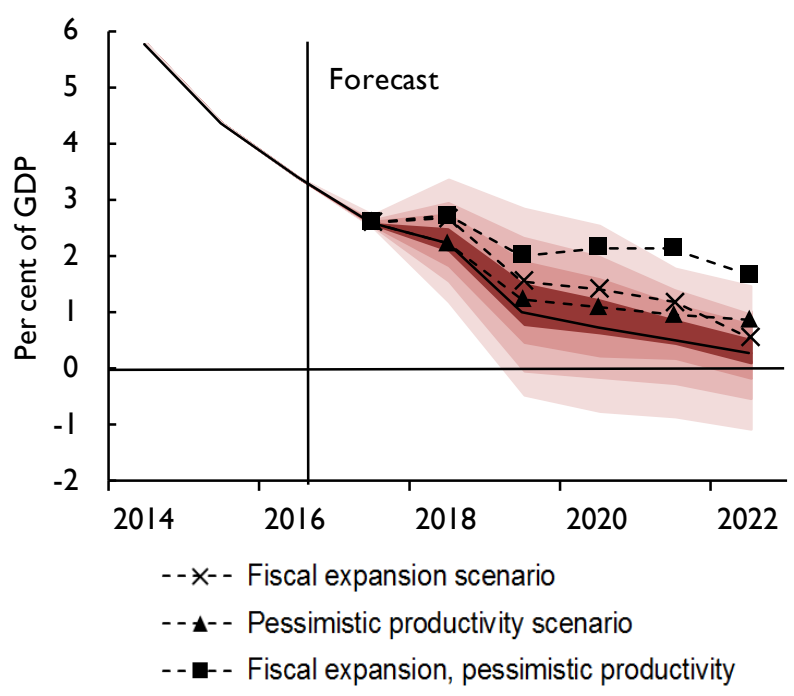

Source: NiGEM database, NiGEM forecast and NiGEM.

Note: The central forecast is based on taxation and spending plans from the 2017 Spring Budget. Each bound represents a cumulative decile of the probability distribution around the November 2017 forecast. The fiscal expansion scenario assumes a positive shock to government spending, welfare transfers and government investment of around $£ 10$ billion in 2018-19 and increases thereafter. 
There are effectively three options: maintain a tight spending policy, seek a higher tax take, or accept that it may not be possible in the next few years to make much further progress towards a balanced budget.

There seems little appetite among the general public for even tighter public spending. Total managed expenditure as a share of GDP is not currently high and the government's existing spending plans already incorporate material further falls. Indeed with reports of 'austerity fatigue', there may already be a preference for higher public spending along the lines built into our higher spending scenario.

There is arguably some scope for higher taxes: for example, some business organisations have suggested postponing the planned reductions in the corporation tax rate. But raising taxes more generally would prove unpalatable in the current political climate.

A preferable option therefore would be to make full use of the fiscal space available within the existing rules to accommodate any continued weakness in productivity. There does appear to be some scope for this response within the existing fiscal framework set out in the 2016 August Statement. This seeks, by 2020-21, to reduce

Figure 4. Probability distribution of public sector net debt

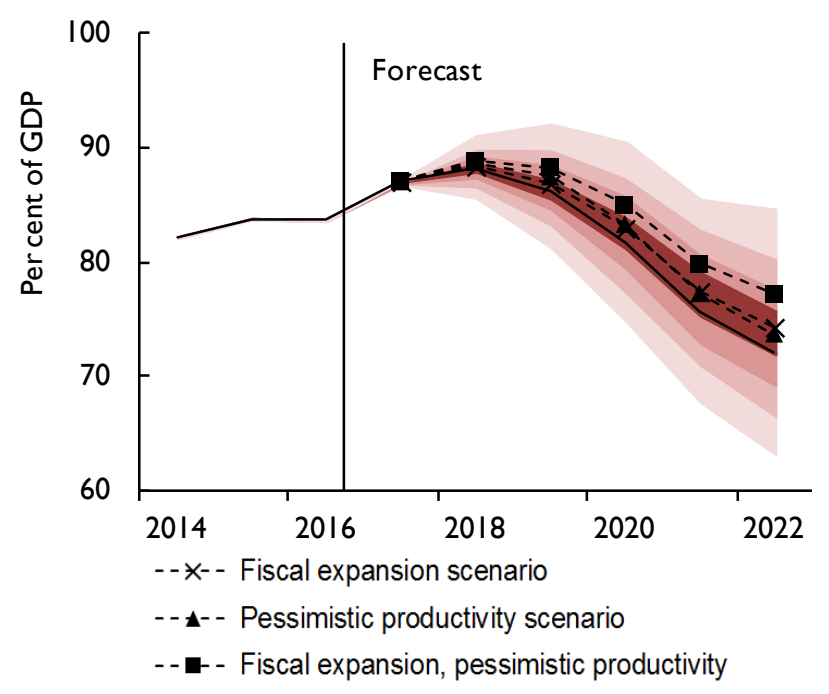

Source: NiGEM database, NiGEM forecast and NiGEM.

Note: The central forecast is based on taxation and spending plans from the 2017 Spring Budget. Each bound represents a cumulative decile of the probability distribution around the November 2017 forecast. The fiscal expansion scenario assumes a positive shock to government spending, welfare transfers and government investment of around $£ \mid 0$ billion in 2018-19 and increases thereafter. cyclically adjusted public sector net borrowing to below 2 per cent of GDP and for public sector net debt as a percentage of GDP to be falling. Our scenario of weaker productivity and higher spending would just about keep net borrowing within the 2 per cent of GDP limit (figure $3)$. While public sector debt is at an uncomfortably high level as a share of GDP, it is expected to fall materially in the central outlook. This was also the case in the OBR's March 2017 Fiscal Outlook, where public sector net debt as a share of GDP was projected to fall by almost 10 percentage points over the next four years. There are also substantial risks to this outlook, as illustrated by the fan chart drawn around our central forecast for net debt as a share of GDP, but these are mostly consistent with it falling from the current financial year onwards (figure 4). This comparatively benign outlook is largely a consequence of the low level of long-term real interest rates relative to the growth rate of GDP that makes the process of fiscal adjustment easier.

This suggests that there is scope at the margin to relax fiscal austerity a little while maintaining long-term fiscal discipline, though this would obviously need to be kept under review.

\section{Monetary policy}

An important factor providing space to delay fiscal consolidation is the low level of interest rates that means that the fiscal arithmetic is relatively benign. This situation looks set to continue even if rates rise from current low levels.

It now looks likely that the Monetary Policy Committee (MPC) will raise Bank Rate at its meeting ending 1 November 2017 and take a small step towards normalising monetary policy. ${ }^{3}$

At its previous meeting in September the MPC clearly signalled that it would raise Bank Rate at one of its next meetings provided that the economy developed as it expected: "a majority of MPC members judged that, if the economy continued to follow a path consistent with the prospect of a continued erosion of slack and a gradual rise in underlying inflationary pressure then, with the further lessening in the trade-off that this would imply, some withdrawal of monetary stimulus was likely to be appropriate over the coming months in order to return inflation sustainably to target". That comment has been widely interpreted to imply a rise at the November meeting.

If the MPC does follow through with the anticipated rate rise then this would also signal that monetary policy 
can be tightened even when economic growth is slow and when the outlook is uncertain. That would reinforce the message that Governor Carney has given on several occasions that there is little that monetary policy can do to offset the real adjustment that Brexit might require: "the biggest determinants of the UK's medium-term prosperity will be the country's new relationship with the EU and the reforms it catalyses. Most of the necessary adjustments are real in nature and therefore not in the gift of central bankers". ${ }^{4}$

Against this background we see further steps towards monetary policy normalisation as being necessary over the forecast period in order to meet the MPC's remit to keep CPI inflation at target. But, according to our central forecast, interest rates do not need to rise very far to achieve that.

\section{Summary}

The UK economy is going through a period of significant uncertainty, with material downside risks as Brexit is being negotiated. In such circumstances it makes sense for individual businesses to postpone investment until there is more clarity about the UK's future relationship with the EU. It also makes sense for some planned fiscal consolidation to be delayed as this can act to offset some of the uncertainty. But there appears to be less reason to postpone the start of the process of monetary policy normalisation: some rise in rates now appears necessary to keep inflation at target.

\section{NOTES}

I Management and Expectations Survey.

2 'Business chiefs demand urgent transition deal', The Guardian, 23 October 2017.

3 Interest rate normalisation was also discussed in the Commentary of the August Review.

4 Mark Carney, Opening remarks to the Bank of England 'Independence - 20 years on' Conference, 28 September, 2017.

\section{REFERENCES}

Bloom, N. and Mizen, P. (20I7), 'New survey evidence on the impact of Brexit on UK firms', VoxEU.org, 5 October 2017.

Bloom, N., Bunn, P., Mizen, P., Smietanka, P., Thwaites, G. and Young, G. (2017), 'Tracking the views of British businesses: evidence from the Decision Maker Panel', Bank of England Quarterly Bulletin, 2017Q2, pp. I I0-20.

Dixit, A. and Pindyck, R. (1994), Investment under Uncertainty, Princeton University Press. 